\title{
Predictive Model for the Factors Influencing International Project Success: A Data Mining Approach
}

\author{
Iulia Dumitrașcu-Băldău ${ }^{1, *}$, Dănuț-Dumitru Dumitrașcu ${ }^{2}$ and Gabriela Dobrotă ${ }^{3}$ \\ 1 Business Administration Department, “Dunarea de Jos” University of Galati, 800008 Galati, Romania \\ 2 Industrial Engineering and Management Department, "Lucian Blaga" University of Sibiu, \\ 550024 Sibiu, Romania; dan.dumitrascu@ulbsibiu.ro \\ 3 Finance and Accounting Department, "Constantin Brancusi" University of Targu Jiu, \\ 210152 Targu Jiu, Romania; gabi.dobrota70@gmail.com \\ * Correspondence: iulia.dumitrascu@ulbsibiu.ro; Tel.: +40-742-351-285
}

\section{check for}

updates

Citation: Dumitrașcu-Băldău, I.; Dumitrașcu, D.-D.; Dobrotă, G.

Predictive Model for the Factors Influencing International Project Success: A Data Mining Approach. Sustainability 2021, 13, 3819. https:// doi.org/10.3390/su13073819

Academic Editors:

Agnieszka Wiśniewska,

Katarzyna Liczmańska-Kopcewicz and Marcin Żemigała

Received: 12 February 2021

Accepted: 24 March 2021

Published: 31 March 2021

Publisher's Note: MDPI stays neutral with regard to jurisdictional claims in published maps and institutional affiliations.

Copyright: (c) 2021 by the authors. Licensee MDPI, Basel, Switzerland. This article is an open access article distributed under the terms and conditions of the Creative Commons Attribution (CC BY) license (https:/ / creativecommons.org/licenses/by/ $4.0 /)$.

\begin{abstract}
Considering that international projects with teams in the virtual environment (IPTVEs) contribute to the reduction in the carbon footprint and, at the same time, become life-saving solutions in extreme global situations, such as the COVID-19 pandemic, organizations familiar with this type of project will have a substantial advantage in their ability to operate efficiently and to achieve their sustainable goals. An important aspect of project management is to identify the factors that influence the success of an international project, increasing its performance. Our first research hypothesis was that the decision to create a project team in the virtual environment is a factor with a major influence on international project success. Data collection was performed through an online survey conducted within international project team members and managers. The success factors were explained through factorial analysis which revealed two main factors and the neural network algorithm on a dataset through IBM SPSS Modeler software. The predictive model revealed that the most important field is setting up a virtual team, followed by organizational culture. These results support our hypothesis.
\end{abstract}

Keywords: international project management; success factors; virtual project team; neural network; data mining; sustainable development

\section{Introduction}

International projects and teams in the virtual environment are a reality of recent years and a growing phenomenon. Despite their increasing presence and advantages in a continuously and rapidly changing environment, the research in the international projects with teams in the virtual environment (IPTVEs) field is still scarce. Thus, the failure rate of international projects has been very high [1], this being confirmed by academic research and, of course, depending on different definitions, which characterizes the failure of a project (the desired results are not obtained; they exceed the budget or the set period of time). Considering the evolution of projects in recent years, Standish Chaos modified in their 2015 report the definition of the success of a project, moving from a definition focused on meeting the constraints of time, cost and scope, to a definition in which it is proposed that success does not necessarily mean the achievement of a predefined objective, but rather a satisfactory result. This change led to a modification in the results of the report, from a success rate of $27-31 \%$ to $36-41 \%$ [2]. "In any sector, a project ought not to be rated successful unless it achieves its relevant objectives efficiently, in a sustainable fashion and with positive impacts, including side effects" [3].

The reduced success rate of IPTVEs is due to their complexity, team diversity, the high risk level, the changes that take place during the development of the project and the impossibility of accurate estimation of time and costs. For this reason, identifying the factors that influence the success of an international project, as well as analyzing their 
behavior, could contribute to the construction of a clearer image on international projects, and companies can be encouraged to get involved in international projects and invest more in setting project teams in the virtual environment, "in order to generate knowledge, stimulating creativity, for creating innovations, having a direct impact on the competitive advantage" [4]. "Many of the empirical studies done on the effect of team diversity on team performance found that it can create added value and deliver higher performance in comparison to homogeneous teams. The reason given is that diversity brings a bordered area of knowledge" [5]. At the same time, a project team in the virtual environment can become an efficient tool for a more sustainable project management, which supports a more sustainable society. Greening project management practices involves the responsible use of resources [6].

The present research is the first to offer empirical information about the influence factors on international project success, which includes one new factor related to a more efficient project team: setting up a project team in the virtual environment. This offers a new perspective on international projects, becoming IPTVEs. This study reveals a strong connection between all the factors included in the research and international project success, by using the data mining process, with special emphasis on setting up a project team in the virtual environment vs. a collocated team and the organizational culture, providing an important pattern which can represent a guide for international project managers to increase the success rate of international projects, since the trained network can be applied to future cases in order to predict international project success. The research did not analyze a particular type of international project based on the activity area, so it can be applied to any IPTVE.

As a result, the paper is structured as follows: Section 2 is dedicated to a literature review; Section 3 presents the methodology; Section 4 continues with data analysis using a modeling technique; Section 5 contains the results obtained, which is followed by a section dedicated to discussion and research limitations, conclusions and future research directions.

\section{Literature Review}

Jean Binder [7] (p. 14) considers that "international projects arise when the projects include people located beyond the country's borders". Köster K. [8] (pp. 27-28) has a broader vision, arguing that international projects are those projects that "generally, cross national borders in terms of the purpose and nationality of the stakeholders".

With the help of international projects, companies are able to transfer new technologies from their partners outside the country's borders while benefiting from their experience and know-how [9]. Atesmen [10] (p. X.) stated that "in today's global economy, we have not found a project that does not have an international component".

Many project managers approach the projects as if all would be the same, considering that they will be successful as long as they follow the standard procedures regarding the classic project management, not taking into account the specificity of each one. Köster K. [8] urges us to change our perspective, moving away from project management standards, to look at international project management as an open system.

Grisham T. W. [11] (p. 67) claims that in a successful international project, the customer satisfaction (quality) has been ensured, and it provides the agreed purpose and falls within the budget and specified time. Additionally, within the IPMA (International Project Management Association) [12], the success of the project is defined as "the appreciation by the different interest groups of the project results". This definition is much more complex than the traditional vision in which success is seen only as obtaining the results of the project respecting the budget and the set time. At the same time, Shenhar and Dvir [13] (p. 25), in order to ensure success, developed and supported a new approach to project management, "a multidimensional model", which goes beyond the triple constraint, based on the idea of "measuring what you receive and on analyzing the benefit investment". On the other hand, this structure has some limitations because the project managers have to take into account other particularities of the international projects. Thus, the risk analysis will be conducted 
taking into account the four new additional dimensions (cooperation, multiculturalism, team dispersion, additional resources), which we have proposed as a specific diamond model for international projects, called "the adapted diamond model" [9]. Regarding the evaluation of the success of projects, in the short and long term, Shenhar and Dvir [14] (pp. 27-30) consider five dimensions: "project efficiency" (in terms of time and budget), "impact on teams" (degree of satisfaction, motivation, development of skills, retention of members), "impact on the customer" (customer satisfaction, customer benefits, extension of use, loyalty, brand recognition), "how the business directly experiences success" (sales, profit, market share, ROI, etc.), "preparing for the future" (new technologies, new markets, new products, new organizational capacity).

Given that "projects are carried out by teams of people, specifically assembled to reach the purpose of the project" [12], in our opinion, the selection process of the team members, as well as the quality of the human resources, will play a decisive role in having a project team with the necessary skills to be able to use the tools provided, to communicate correctly and efficiently and to adapt to a virtual work environment, thus managing to ensure the success of the international project. "Project management should ensure that individuals have the technical, behavioral and contextual competencies and that they are provided with the appropriate information, tools and training to be able to perform the required tasks effectively" [12].

To ensure the success of IPTVEs, organizations need to know first how to build a team in the virtual environment, understand how it works, its advantages and its disadvantages and also take into consideration different factors according to international project characteristics. Thus, as a result of the bibliographic research, the following factors influencing the success of the international project were analyzed:

- External environmental factors (political, legal, economic, socio-cultural, demographic, technological factors, natural and international environment). The components of the external environment of the international project are identified as the environmental factors of the organizations that carry out the project, including those components that cannot be controlled by the project team and that influence, constrain or direct the project. The international economic environment, as a result of the globalization process, requires increasing competitiveness of the companies in order to be able to resist and develop in the global economic markets. As a result of this phenomenon, the project management must adapt to new features of the project and take into account an increased degree of risk generated by the high degree of complexity, determined by the diversity of stakeholders, the numerous financial differences regarding foreign exchange, interest rates, inflation, taxes and duties, geographical location, time zone differences regarding banks' activity, legal holidays, etc. The national and international political environment includes the actions of the countries' governments in which the organizations that collaborate in the international project are registered or carry out their activity, which can influence their operations. The actions can take place at the local, regional, national and international levels. Governments can influence certain important areas by controlling infrastructure, supplying raw materials, stimulating policies for local producers, limiting imports and boosting exports. At the international level, the political environment is complemented by the actions and instability of political unions. The legal environment can have an influence, through different laws and restrictions, on security, data protection, the labor market or the supply of different resources. There may also be different standards regarding production, quality of deliverables or environmental protection, which must be taken into account in the project planning phase. In addition to those mentioned, Popa I. [14] (p. 137) considers that "in this sphere is included the influence exercised, on various channels, by companies and groups of companies with common interests, on the institutional bodies with prerogatives in the field of drafting, substantiating and adopting laws and the other regulatory acts, in order to orient their provisions according to the mentioned interests" [14] (p. 137). The educational environment. Education plays a very impor- 
tant role, influencing the quality of human resources. Knowing the social situation, level of education stimulation and other aspects makes efficient planning of the project and prediction of its success easier [15]. Additionally, the academic environment can represent an indirect influence, through opportunities for collaboration, specific studies and publications, which can contribute to the fulfillment of the objectives and the purpose of the international project. The social environment includes all the persons who can be affected by the system, without initially being stakeholders of the project (clients or users). The cultural environment includes codes of conduct, ethics and stakeholder perceptions. Lahiri and Dhandapani [16] investigated how the cultural distance between foreign multinational enterprises of home and host nations, and the business group affiliation of the host country partner influence the duration and completion likelihood of capacity expansion projects, identifying the fact that a high cultural distance is associated with lower project duration and greater likelihood of project completion. The natural environment, in particular, refers to the access to natural resources and how each country assesses ecological issues. "There are countries with very high ecological development, but there are countries where ecology is not the index of the upper class. It is very difficult to expect long-term success or effective implementation of the project without saving the ecological environment and the environmental protection functions" [15]. The demographic environment generally refers to age, gender, level of education, economic activity [17], position within the organization, project duration, respondents' certification status and region of the world where respondents are located [18]. The demographic profile of the person leading a project affects how he or she perceives the relative importance of the various project success factors [18]. Technological environment: innovation is directly proportional to the increase in productivity and competitiveness. Thus, at present, the innovation capacity of an organization becomes an additional resource, in addition to the financial, commercial and productive capacity. "Although all the world is rapidly going forward together with modern technologies, situation of technology development in different countries may vary, innovations created in one country are reaching other countries at different rates, also not all innovations and technologies created in the countries are standing up or entrenching" [15].

- Leadership style. Grisham T.W. [11] (p. 8) states that "international project management represents the leadership of projects in multiple countries and cultures". Through this statement, Grisham T. W. [11] draws a clear line between international project management and leadership, considering that the success of international projects will be ensured by $80 \%$ leadership (soft skills) and 20\% management (hard skills). Yang, L.-R., Huang, C.-F. and Wu, K.-S. [19] claim that "some project managers develop particular leadership behaviors in an attempt to improve the performance of a project", and their research revealed that "increases in levels of leadership may enhance relationships among team members". "Leadership involves providing direction and motivation to others in fulfilling their tasks and roles, in order to achieve the project objectives" [12]. In contrast, many project managers continue to rely exclusively on so-called "hard skills", such as planning, scheduling and controlling, to coordinate projects [7]. The project manager must understand and anticipate the effects of the decisions which he/she makes within the projects on all interested groups. Additionally, his/her vision must be a long-term one, in order to act correctly and coherently, taking into account the experiences of the past and the present and the anticipation of future effects. "Being a leader for the team members represents the most important aspect of the work of a project manager, followed closely by the communication skills. Project management is only the third place, according to our experience" [11] (p. 12).

- Organizational culture. Given that the organizations involved in the development of the international project can influence the project culture, through their own culture, we consider that the dimensions of the organizational culture can be used to describe 
a cultural model of the international project, which will support the performance of the project team and ensure its success. Organizational culture is defined as "the way in which the members of an organization relate to each other, to their work and to the external environment, as compared to other organizations. These dimensions allow a tangible alignment of organizational culture and strategic objectives" [20].

- Correct and clear definition of the international project purpose and objectives. International projects have emerged as a response to the phenomenon of globalization and technological innovation, and as a result, their purpose is oriented to the opportunities offered by the expansion of these phenomena. The purpose refers to all the activities involved in the creation of the final product and the processes used in this regard. The holders of interests must reach a consensus on the final product and how it is made [21]. One of the most important goals of international projects is the access to limited resources. This can refer to collaborators from outside the borders, who provide new technological processes, patents and know-how, to the acquisition of foreign companies, who have important knowledge regarding the national markets where they operate, and to members of the dispersed project team, located anywhere in the world, capable of carrying out activities, which together will contribute to achieving the proposed objectives. Grisham T.W. [11] (p. 21) states that people and material sources for international projects come from the global level. As the scope of the international project integrates several objectives of increased strategic importance, its degree of complexity increases, due to the increasing difficulty in defining and understanding it, in order to be correctly assimilated by the members of the dispersed project team.

- $\quad$ The triple constraint (meeting the quality criteria; budget constraints; time constraints). Each project is constrained in different ways by the purpose, duration and cost of the objectives. These limitations are called the triple constraint by the traditional project management. According to this belief, in order to create a successful project, the purpose, duration and cost must be fully considered and represent the balance that any project must pursue in order to be considered successful [21] (p.14). In our opinion, the evaluation of the success of an international project should be related, first of all, to the fulfillment of the quality requirements regarding the deliverables and the customer satisfaction and less to the other two, the most rigid points of the triple constraint: the time and the cost, as mentioned in the first part of the introduction. "Quality is normally sacrificed when a project exceeds time or budget" [22]. Additionally, Thomas, G. and Fernández, W. [23] stated that "given the human tendency to underestimate challenges and to overestimate their own capabilities, stakeholders could perceive as a partial failure a project that was in fact successful in achieving near-optimal results". In this research, each component of the triple constraint will be analyzed.

- Setting up a team in the virtual environment vs. collocated team. "As a result of technological advance, companies are forced to look for innovative ways to adapt and incorporate virtual teams" [24]. "More than any other factor, information technology has allowed the proliferation of teams in the virtual environment. With mobile devices, text messaging, electronic learning modules, cloud computing, team members can interact in a much more accessible way, anywhere and anytime" [25] (p. 16). Thus, "virtual project teams are becoming common organizational structures because firms seek to leverage geographically distributed, specialized knowledge to execute work" [26]. Brewer P. E. [27] (p. 130) suggests that "teams in the virtual environment have become essential elements in successful organizations. Where it does not exist, the opportunity is lost. Where it does not work effectively, the opportunity is lost. International teams in the virtual environment are the key to some of the greatest successes and failures in the global work environment, while the organization learns to function as a complex network of people". In addition, many of the companies that initiate international projects develop sustainable strategies, in order to align with the international environmental protection policies, supporting sustainable development, 
and the teams from the virtual environment can play a very important role, acquiring the title of "green job" [28], taking into account that one of the advantages of these teams is the reduction in the carbon footprint [4]. "Organizations, only now, are beginning to realize that specialized skills and competencies are needed to effectively manage teams in the virtual environment, being considered more important than establishing the best combination of collaborative technological tools used in the virtual environment" [29] (p. Xiii).

Regarding the definition of the team in the virtual environment, we consider that, beside the fact that it is a team that carries out most of its activity, remotely, through technology, as opposed to performing tasks in face-to-face contexts [27], it is necessary to mention that this communication made through electronic instruments does not transform a group of people into a team [28], for which the idea of Lee R. Margaret [30] (p. 2) becomes essential, claiming that "these virtual teams share a common work, product or project purpose". "As the members of the project team work in the context of a project, there is a beginning and an end time of work and time, which they will spend together as a team, well established" [31]. This research relates only to international project teams in the virtual environment and not to a group of people who work together regularly, geographically dispersed. Although project teams in the virtual environment are very different from traditional, collocated teams, project managers, most of the time, act in the same way, considering that what works in a collocated team can be equally useful in the virtual environment. This approach can only be extremely erroneous, given that "the virtual environment amplifies the most difficult aspects of team management" [32] (p. 20), leading, in most cases, to an inefficient team and, implicitly, to the failure of the international project.

Following certain causes that lead to the failure of international projects, identified in the literature, the starting point in the research carried out is the idea that the lack of performance of the project management is due to a poor management and performance of the project team, particularly of the international project team in the virtual environment. The central objective of the research is the validation of the factors that influence international project success, as well as the analysis of their behavior. The influence factors will be analyzed through the sociological survey, based on the data collected through a questionnaire, by statistical analysis and, subsequently, mathematical modeling. Thus, the research hypotheses are as follows:

Hypothesis 1 (H1). Building a project team in the virtual environment and its efficient management have a major impact on international project success.

Hypothesis 2 (H2). The correct and clear definition of the scope and objectives of the international project, which reflect its scale and complexity, contributes to ensuring international project success.

Hypothesis $3 \mathbf{~ ( H 3 ) . ~ A ~ f l e x i b l e ~ a p p r o a c h ~ t o ~ p r o j e c t ~ m a n a g e m e n t , ~ w h i c h ~ g o e s ~ b e y o n d ~ t h e ~ t r i p l e ~}$ constraint, contributes to international project success.

\section{Materials and Methods}

\subsection{Methodology}

The research methodology comprises two stages. The first stage is based on descriptive research in which information was collected from secondary sources, such as books, scientific articles and studies. The bibliographic analysis was the basis for the description of the existing situation regarding the success of IPTVEs, managing to create a detailed image on the researched field, in order to clearly formulate the hypotheses of the empirical study.

During the second stage of the reasearch, we took a quantitative approach using a survey, with the self-administered opinion questionnaire as the research tool, created through the Google Forms service and sent directly to the subjects in the form of an access 
link. The questionnaire was designed based on the information related to the factors of influence on the success of IPTVEs, obtained from the bibliographic research. The universe of the population comprises individuals who have performed or are operating within an IPTVE. For the analysis of the collected quantitative data, we used the software IBM SPSS Statistics and IBM SPSS Modeler. The modeling technique analyzed the behavior of the different factors of influence, which allowed the creation of a predictive model.

The sample is non-probabilistic given that there are no official data for the entire population [28]. The selection was rational [33] based on the reasoning of the interview operator that the respondent represents the population of interest, but also on the technique of "snowball" in which research participants recruit other study members [34], such as teammates within the same project.

The variables used in the modeling process were obtained from the first question of the questionnaire. The question was designed in the form of a 5-point Likert scale (Table 1).

Table 1. Likert scale used in the first question of the survey.

\begin{tabular}{ccccc}
\hline $\mathbf{1}$ & $\mathbf{2}$ & $\mathbf{3}$ & $\mathbf{4}$ & $\mathbf{5}$ \\
\hline Not at all & To little extent & To some extent & To a large extent & To a very large extent \\
\hline
\end{tabular}

\subsection{Sample Description}

The research sample is composed of 107 respondents, $43.9 \%$ male, 59\% female and $0.9 \%$ who preferred not to respond. Subjects have different nationalities-86 Romanian and 18 other nationalities (Spanish, Turkish, Pakistani, Swedish, Slovakian, Ukrainian, Armenian, Malaysian, Bangladeshi, Indian, Australian, American, Chilean, Costa Rican, Guatemalan). They are part of an IPTVE which takes place over different periods of time, and most of the respondents (39.3\%) correspond to the "over 18 months" category, a characteristic for complex projects. Regarding the roles distribution of the respondents in the international projects, it was revealed that $56.1 \%$ of the respondents are members of the team management. Most respondents (65.42\%) in each of the three roles were found in the $31-40$ age group (22.43\% are project managers, $15.89 \%$ team leaders and $27.10 \%$ team members). For the distribution of respondents by level of education and position occupied within the project, the majority of respondents were grouped in the higher education category, especially at master level $(43.9 \%$, of which $11.21 \%$ are project managers) and bachelor level (42.06\%, of which $16.82 \%$ are project managers).

As regards the experience in the international projects and in the virtual project teams, we created cluster diagrams which revealed that $61.68 \%$ of the respondents have more than 5 years of experience in international projects, project managers being distributed in the upper part of the diagram, especially in the "10-20 years of experience" category. This assures us that the data collected in the research are relevant. Concerning the experience within the project teams in the virtual environment, $37.38 \%$ of the respondents have over 5 years of experience, of which $18.69 \%$ take the role of project manager.

Teams in IPTVEs include members who operate remotely, working in different time zones and using electronic tools. The survey sample confirmed these time differences, with $92.52 \%$ of the subjects replying that there was a time zone difference of at least one hour between them and the rest of their colleagues [28].

\subsection{Variable Description}

Following the results shown in Figure 1, it can be distinguished that all eight variables are represented by over $90 \%$ of responses that confirm their influence on the success of international projects. It can also be noted that "the correct and clear definition of the scope and objectives of the international project" represents the main option of the respondents, $54.21 \%$ considering that it influences to a very large extent and $31.78 \%$ to a large extent, followed by "leadership style" and "meeting the quality criteria". At the opposite end, there are "the external factors" and "setting up a team in the virtual environment vs. a 
traditional team", although it should be specified that both factors presented the highest share of the responses considered neutral or indecisive- $42.06 \%$ and $40.19 \%$, respectively, of the respondents who chose "moderate" - which may be due to the lack of information regarding the influence that these factors can have on the success of an international project. These results support the second and third assumptions of this research.

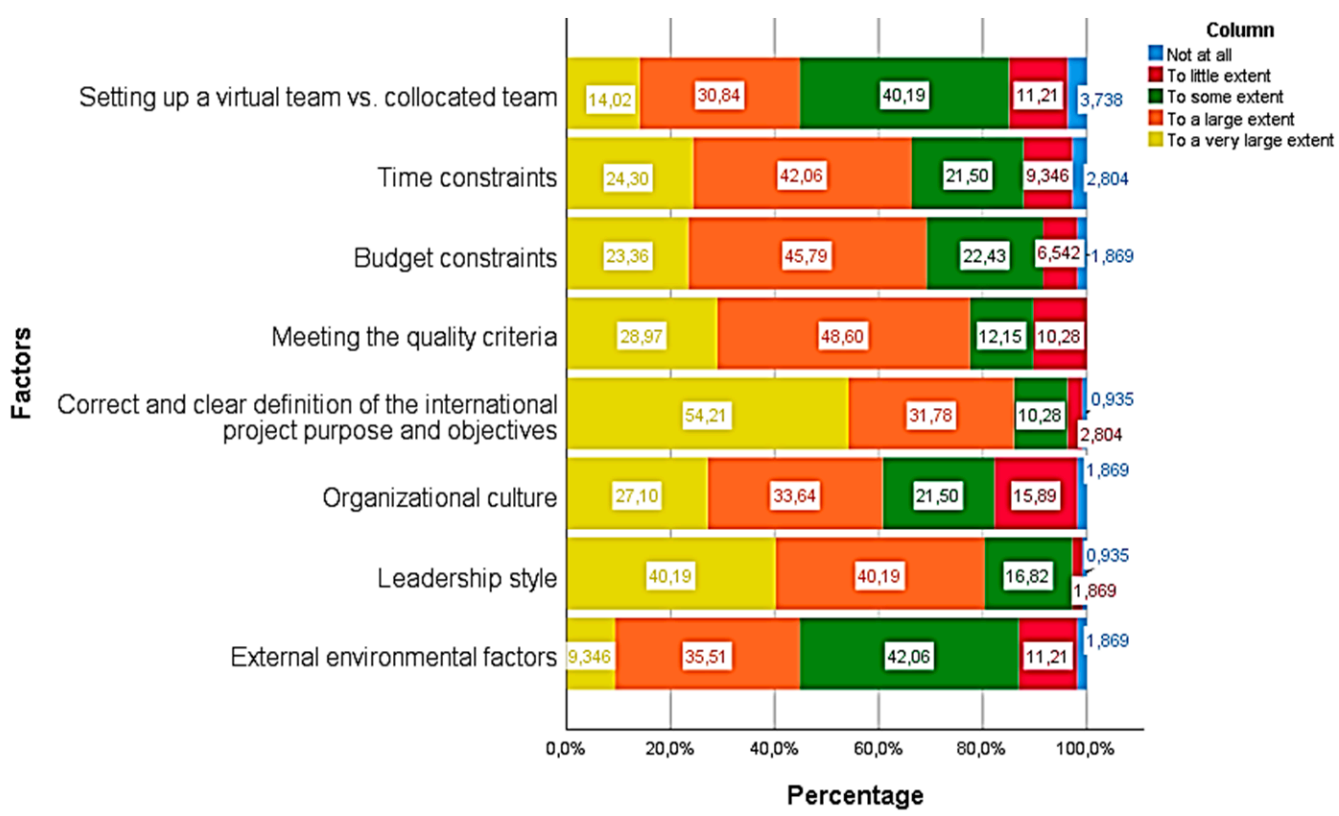

Figure 1. To what extent do you consider that the success of the international project depends on the following aspects? Source: authors.

At the question in which the subjects are asked to order the answers regarding the main areas responsible for the failure of international projects, $48.60 \%$ of the respondents stated that the team is in first place, $46.73 \%$ opted for processes as the second area generating project failure and $57.94 \%$ placed the customer in last place (Figure 2). These results confirm the existence of a strong interdependence between the success of the international project and the performance of the project team, supporting the first research hypothesis.

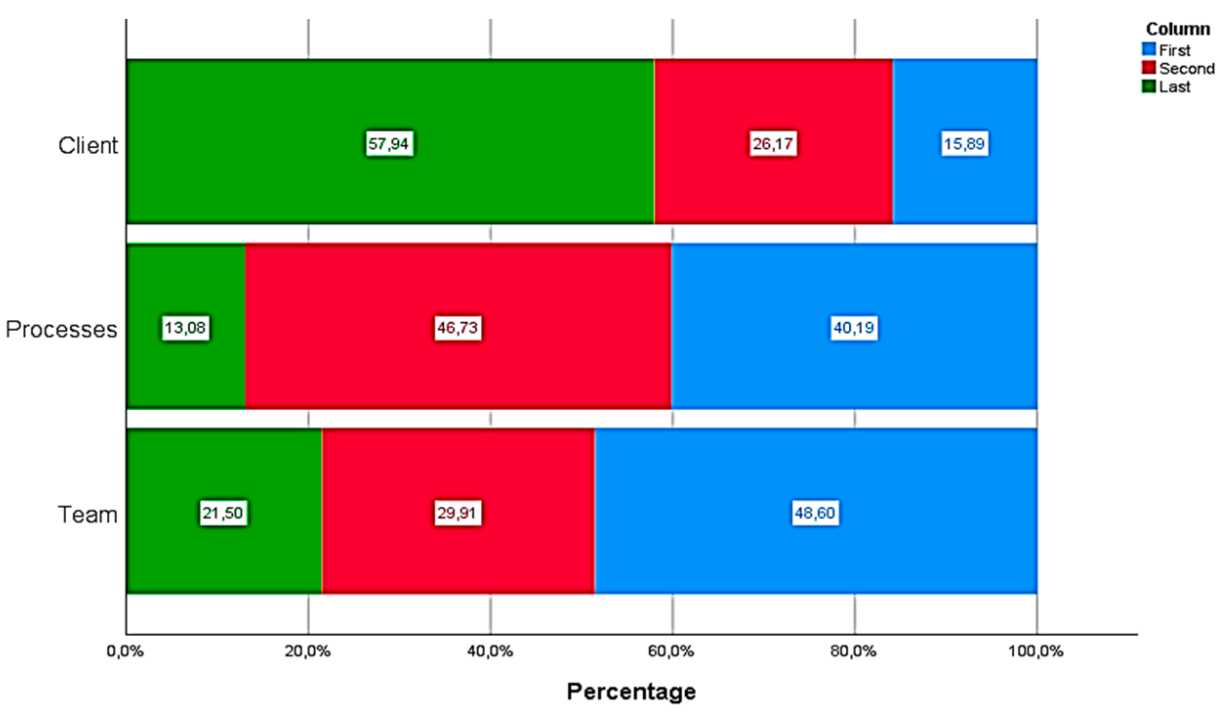

Figure 2. In your opinion, what are the main areas that lead to the failure of international projects? (prioritize options). Source: authors. 


\section{Data Analysis Using Modeling Techniques}

\subsection{Conceptual Elements on Modeling Technique Using IBM SPSS Modeler Software}

In order to reveal and understand the influence that the factors analyzed can have on international project success, the data collected through the questionnaire-based survey method will be processed using the modeling technique through IBM SPSS Modeler software, building a predictive model. Data mining represents a result of the discovery and interpretation of existing patterns in the data and it creates new knowledge in a natural or artificial form. The artificial knowledge comes in the form of a predictive model [35] (pp. 3-4).

Stream canvas is the main area of work within the program, where nodes and other types of icons can be usefully placed in the modeling process. The nodes represent operations, which will be performed on the data. As soon as the nodes have been placed on the stream canvas, they can be joined together to form a stream.

There are general rules for constructing modeling flows, especially regarding the order of connection of nodes. Thus, a flow will always start with a source node (circular nodes) and will contain processing nodes and terminal nodes. The processing nodes prepare the data and are found in "Record ops" and "Field ops" (hexagonal palettes). The terminal nodes are those in the form of a triangle (Graphs palette), pentagon (Modeling palette) or square (Output and Export palettes) [36] (pp. 45-46).

\subsection{Preparing Data for Processing}

The data preparation phase is one of the most important and time-consuming parts of the data mining project [36] (p. 30). In IBM SPSS Modeler, data can be read from a wide variety of sources. In this case, it was decided to use Microsoft Excel as a source; therefore, the data were restructured and adapted for this format and the analysis on the model components evaluated in question number one. Each of these components is broken down into factors, which were identified within the factorial analysis, and their characteristics, represented by the variables whose numerical attributes were obtained through the questionnaire. The factorial analysis revealed two main factors, taking into account the values corresponding to the variables with loads and correlations $>=0.50$, renaming them as follows: the first factor, "Project Management", and the second factor, "External Factors" (Table 2).

Table 2. Decomposition of components into factors and characteristics. Source: authors.

\begin{tabular}{|c|c|c|c|c|c|}
\hline Component & Factors & Characteristics & Mean/Characteristic & Mean/Factor & Mean/Component \\
\hline \multirow[t]{8}{*}{$\begin{array}{l}\text { International } \\
\text { project success }\end{array}$} & $\begin{array}{l}\text { External } \\
\text { Factors }\end{array}$ & $\begin{array}{l}\text { External environment of the } \\
\text { project (political, legal, economic, } \\
\text { socio-cultural, demographic, } \\
\text { technological, natural, } \\
\text { international factors) }\end{array}$ & 3.393 & 3.398 & 3.818 \\
\hline & & $\begin{array}{l}\text { Building a project team: } \\
\text { setting up a virtual team } \\
\text { vs. collocated team }\end{array}$ & 3.402 & & \\
\hline & $\begin{array}{c}\text { Project } \\
\text { Management }\end{array}$ & Leadership style & 4.168 & 3.958 & \\
\hline & & $\begin{array}{l}\text { Correct and clear definition of } \\
\text { the international project scope } \\
\text { and objectives }\end{array}$ & 4.355 & & \\
\hline & & Meeting the quality criteria & 3.963 & & \\
\hline & & Budget constraints & 3.822 & & \\
\hline & & Time constraints & 3.757 & & \\
\hline & & Organizational culture & 3.682 & & \\
\hline
\end{tabular}


In the modeling process, it is very important to correctly define the size of each variable using the "Type" hex node in the "Field Ops" palette [37] (pp. 7-8). Moving on, the "Type" node, connected to the source file, will help to establish the role of each variable in the modeling process, namely, variables of type "input" or "target", and their values can be read [37] (p. 27). Later, the Type node can be connected to an output-type node-Table-to explore the existing data in the source file.

As stated before, the values of the "ordinal" variables having the role of "input" were obtained from data collected through the questionnaire, but in order to perform the modeling analysis, it was necessary to create a "target" variable, which was called "Model" and was registered as a "flag" type because it received binary values " 1 " / " 0 ". These values were calculated for each instance, based on the weighted average value of each component, which can be viewed in Table 2, so that the variable "Model" received the value " 1 " if the average value of the instance is equal to or greater than the average value of the analyzed component. Otherwise, it received the value " 0 ". Each questionnaire represents an instance of the behavior of the group of variables, which are part of a component.

\section{Results}

To create the modeling stream, first, a source node was used, the Excel type (Figure 3), in order to be able to access the data on the subjects' answers to question number one, regarding the influencing factors on international project success. In order to view and verify the data, the source node was connected to the output node-Table.

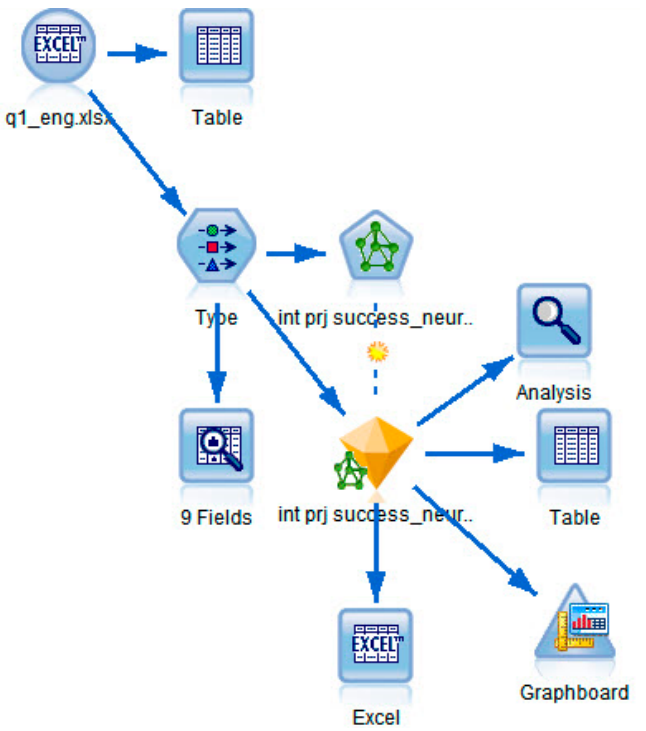

Figure 3. The modeling stream on the behavior of factors that influence international project success. Source: authors.

Subsequently, the source node was connected to the Type node, in the Field Ops palette, to prepare the data for modeling, determining how to measure each variable (characteristic of the analyzed factors), as well as its role (Figure 4).

\begin{tabular}{|c|c|c|c|c|c|}
\hline Field & Measurement & Values & Missing & Check & Role \\
\hline$\langle A\rangle$ Organization... & Ordinal & $1.0,2.0,3 \ldots$ & & None & \Input \\
\hline$\langle$ A Correct and. & Ordinal & $1.0,2.0,3 \ldots$ & & None & \Input \\
\hline A $\geqslant$ Meeting the ... & Ordinal & $2.0,3.0,4 \ldots$ & & None & Input \\
\hline (it) Budget cons... & Ordinal & $1.0,2.0,3 \ldots$ & & None & $\searrow$ Input \\
\hline$\langle$ in Time constr... & Ordinal & $1.0,2.0,3 \ldots$ & & None & \Input \\
\hline$\langle\hat{\#}\rangle$ Setting up a ... & Ordinal & $1.0,2.0,3 \ldots$ & & None & \Input \\
\hline स्स Media & Continuous & {$[1.5,5.0]$} & & None & Q None \\
\hline 陆〉 Model $(>=3,8 \ldots$ & Flag & $1.0 / 0.0$ & & None & (2) Target \\
\hline
\end{tabular}

Figure 4. Data preparation through the Type node. Source: authors. 
Following the modeling stream in Figure 3, it can be seen that the Type node was connected to the Neural Network modeling node of the classification type. A neural network is a simplified model of how the human brain processes information. The basic units are the neurons, which are usually organized in layers. It works by simulating a large number of interconnected processing units that resemble abstract versions of neurons [38]. A neural network can approximate a very large range of predictive models with minimal requirements on model structure and hypotheses. The structure of relationships is determined during the learning process. If there is a linear relationship between the target and the predictors, then the results of the neural network should approximate those of a traditional linear model. If there is a nonlinear relationship, then the neural network will automatically approximate the structure of the appropriate model. Usually, interpreting a neural network is not easy, but predictions are the best [39] (p. 113).

After choosing the modeling node, it can be edited by setting the objectives and other options of the model. In this case, the objective chosen is to build a new model, namely, a standard one. This involves creating a unique model to predict the target, based on predictors. Additionally, it was established that the network will be a multilayered one, which allows for the presentation of complex relationships between variables.

After executing the modeling node, a "nugget" of the model was generated, through which the data on the predictive model can be visualized. The model summary (Figure 5) contains data on the target, the type of neural network - in our case, multilayer-the rule stopping algorithm - in this case, it was stopped due to the fact that the error in the overlay prevention set could not be reduced after each cycle-and the number of neurons in each cycle of hidden layers in the network - in this case, four neurons. The hidden layer of a neural network contains unobservable units. The value of each hidden unit represents certain functions of the predictors; the exact form of each function depends on the type of network. The number of layers was automatically chosen by the algorithm.

Model Summary

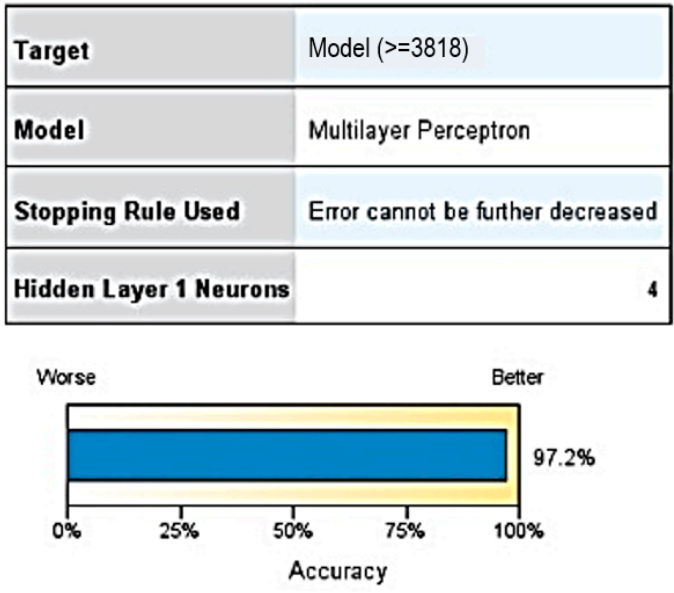

Figure 5. Model summary. Source: authors.

Regarding the quality of the neural network, the diagram shows the accuracy of the final model-in this case $97.2 \%$. This represents the percentage of records for which the predicted value equals the observed value.

In the next window of the results regarding the predictive model, the chart "importance of the predictor" is displayed (Figure 6), which shows the relative importance of each predictor in the estimation of the model. The values are relative, so their total sum is 1. Within the obtained model, the most important predictor is "Build a project team: setting up a virtual team vs. collocated team", followed by the organizational culture and the budget constraints, while the other predictors have similar levels regarding their importance in the predictive model. These results support the first research hypothesis. Additionally, it must be mentioned that both factors, called "External Factors" and "Project 
Management", are of high importance, by the presence of characteristics of both categories at the top of the diagram.

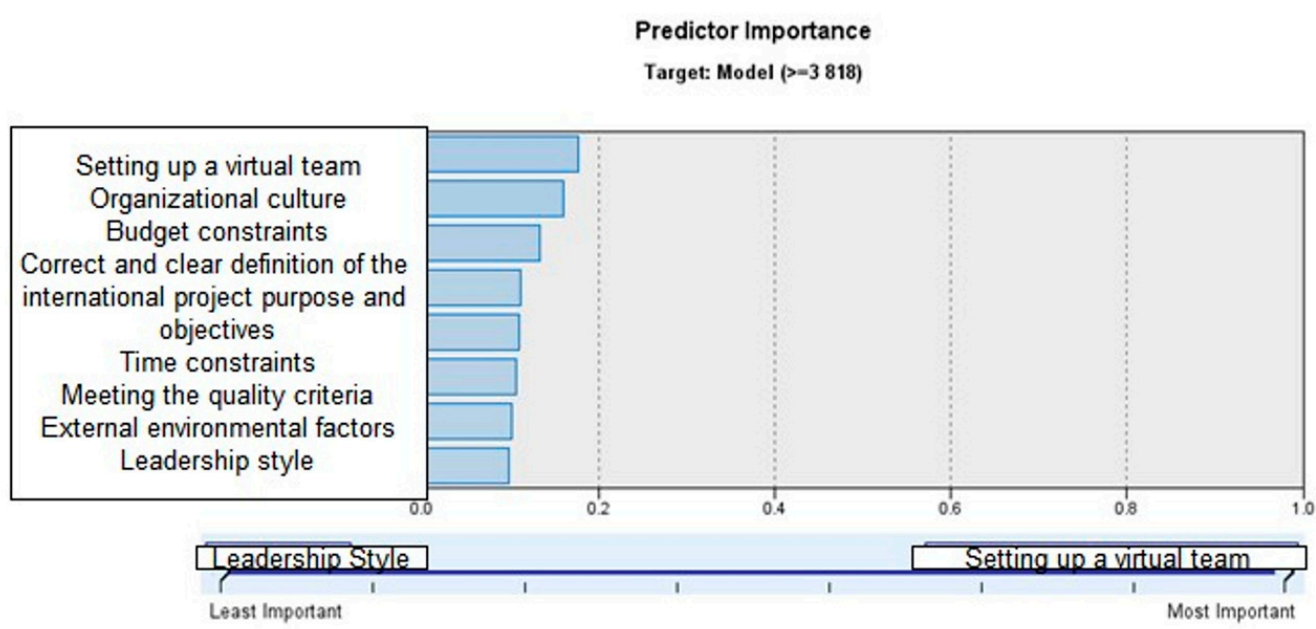

Figure 6. Predictor importance. Source: authors.

In the window regarding the classification model (Figure 7), the cross-classification of the observed values against the predicted ones is displayed in the table, in a thermal map. The percentage of correctness is $100 \%$.

\section{Classification for Model $(>=\mathbf{3 8 1 8}$ ) \\ Overall Percent Correct $=\mathbf{1 0 0 . 0} \%$}

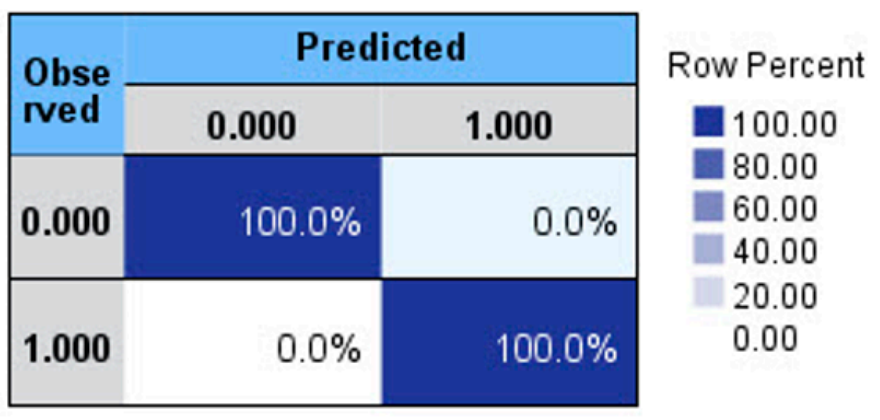

Figure 7. Classification model. Source: authors.

In the last window of the model, the graphical representation of the neural network obtained is displayed (Figure 8).

It can be seen that there is a fully connected neural network which associated a weight with the connection of each input neuron and hidden neuron [40] (p. 748), meaning each output unit depends on each input unit. The connection lines have different loads, depending on the importance of the predictor; a larger line width corresponds to a higher importance. It can be seen very clearly that the connection lines of the first three predictors are thicker. The processing units are arranged in layers: an input layer, with units representing the input fields (nine fields, including Bias); a hidden layer; and an output layer, with a unit representing the target field-Model. The input data are presented to the first layer and the values are propagated from neuron to neuron in the next layer. Bias represents an extra neuron included with each pre-output layer and stores the value of " 1 " for each action. Bias units are not tied to any previous layer in the network, so they do not represent any 
form of activity but are treated the same as any other weight. Bias serves as the execution of a threshold value and determines whether or not a neuron will be activated [41]. The network learns through training, by examining individual records, generating a prediction for each record, and making weight adjustments whenever it makes an incorrect prediction. This process is repeated several times, and the network continues to improve its predictions until the stop criterion has been met. Examples for which output is known are repeatedly presented in the network and the answers they provide are compared with known results. The information in this comparison is transmitted through the network, gradually changing the weights. As the training progresses, the network becomes more and more accurate in reproducing the known results. Once trained, the network can be applied to future cases where the result is not known [38].

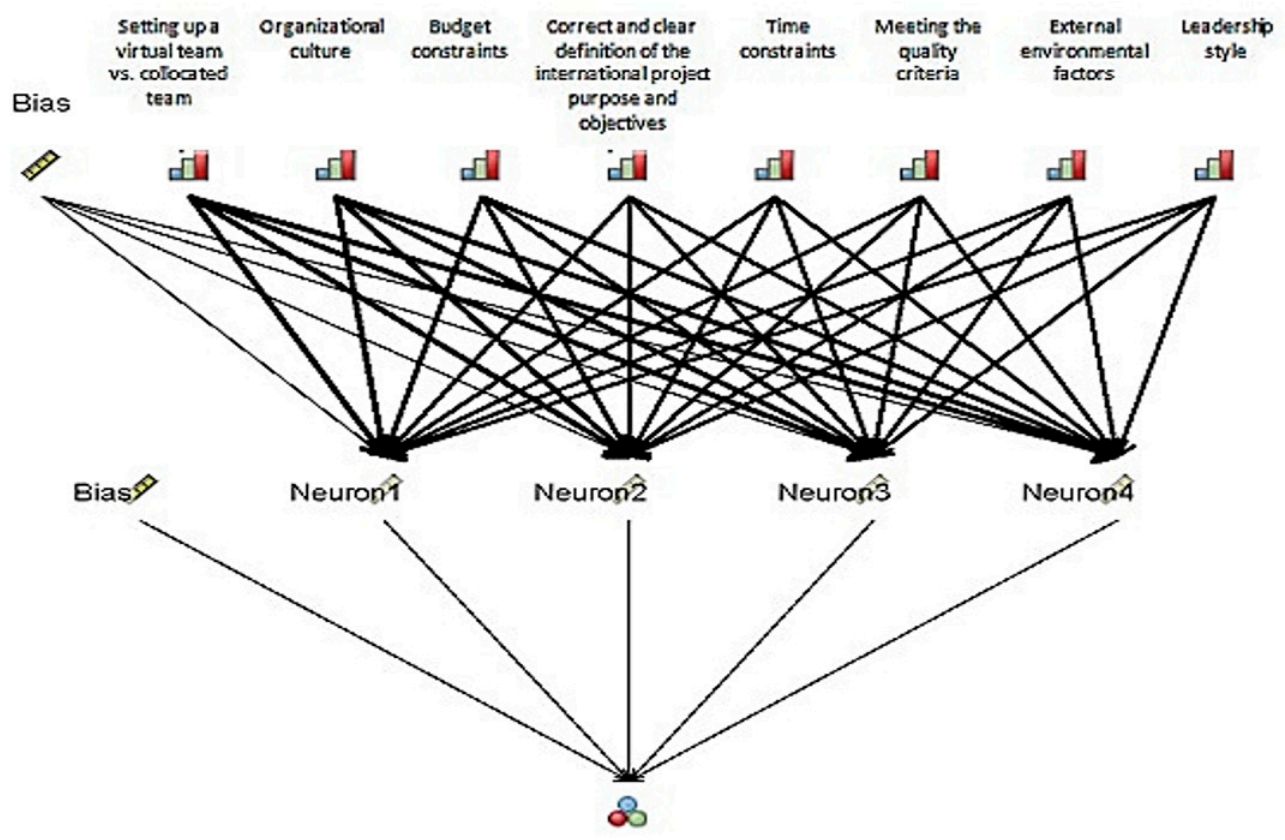

Model

$(>=3818)$

Figure 8. The neural network—the success of the international project. Source: authors.

The results obtained offer very important information. The predictive model shows that international project success is influenced by each factor analyzed, so their importance should not be ignored, although their importance is different, and they should be prioritized when planning and managing the international project. First of all, setting up a team in the virtual environment vs. a collocated team has the biggest impact on international project success, highlighting, once again, the fact that the project team is the most important area whose performance can contribute to a higher rate of project success and that technology provides the key to making the team more efficient in this particular context. Secondly, the "organizational culture" factor also refers to the team and how it performs, depending on how the team members interact with each other and their relationship with the outside. Thus, this result highlights the importance of defining the dimensions of organizational culture that can be used to describe a cultural model of the IPTVE, which will support the performance of the project team and ensure its success. In the third line, the "budget constraints" factor shows that international project success still depends on the traditional triple constraint, since also the "time constraint" factor has a bigger impact on predicting international project success than "meeting the quality criteria". This means that our third assumption is not supported by the neural network predictive model. Regarding the "correct and clear definition of the international project scope and objectives" factor, it ranks fourth in importance in predicting international project success. This supports the 
second research hypothesis and it also relates, indirectly, to the project team performance. As the scope of an IPTVE includes several objectives of increasing strategic importance, its degree of complexity increases, as a result of increasing difficulty in defining and understanding it, in order to be correctly assimilated by the project team members in the virtual environment, and this is also due to the challenges raised from the characteristics of the virtual environment, especially those related to communication.

Returning to Figure 3, it will be noticed that the model nugget obtained was connected to an output-type node, called "Analysis", through which the accuracy of the predictive model was evaluated (Figure 9). This type of node evaluates the ability of a model to generate accurate predictions, making comparisons between estimated and actual values, within the target field. Thus, the predictive model obtained has a level of precision of $97.2 \%$. As for the metric evaluation, it is only available for binary classifiers and reports the values of the area under the curve (AUC) and those of the evaluation of the Gini coefficients. The AUC and Gini coefficients are always between 0 and 1, and the closer the value is to 1, the better the classifier. A receiver operating characteristics ROC curve diagonal between coordinates (0.0) and (1.1) represents a random classifier and has an AUC of 0.5. Thus, a realistic classifier will have no AUC less than 0.5. The Gini coefficient will be negative in the unlikely event that the ROC curve is below the diagonal [42]. Regarding the model analyzed, the AUC and Gini values are 1, which means that the predictive classification model is very good.

\section{Results for output field Model ( $>=3818$ ) 甶. Individual Models$$
\text { 白. Comparing \$N-Model ( }>=3818 \text { ) with Model }(>=3818)
$$

\begin{tabular}{|l|r|r|}
\hline Correct & 104 & $97.2 \%$ \\
\hline Wrong & 3 & $2.8 \%$ \\
\hline Total & 107 & \\
\hline
\end{tabular} \\ Evaluation Metrics

\begin{tabular}{|l|r|r|}
\hline Model & AUC & Gini \\
\hline \$N-Model (>=3818) & 1.0 & 1.0 \\
\hline
\end{tabular}

Figure 9. Predictive model evaluation. Source: authors.

\section{Discussion and Research Limitations}

The results of this research highlight that setting up a team in the virtual environment vs. a collocated team has the biggest impact on international project success, which also supports the fact that the project team is the most important area whose performance can contribute to a higher rate of project success. This last idea is also found in the results of other studies on project success factors. As we have already stated, the specific literature explicitly addressed to international projects with teams in the virtual environment is extremely limited. Thus, the related works include the literature regarding international project success factors, which are generally focused on construction and development projects.

The study conducted by Tran K.T. [43] on critical success factors in international projects, using a regression model with four independent variables (conditions, capacity, commitments and communication), revealed that project team capacity is considered a prerequisite for the project success, along with project manager capacity. This research does not distinguish between different types of teams, so authors do not define the team as being collocated or set in a virtual environment. However, the results obtained focus on the project team impact on international project success.

Alashwal, A. M., Fareed, N. F. and Al-obaidi K. M. [44] conducted research on success factors in construction projects using the PCA method. Six components were identified as 
important in the study. The most significant component was power and skills of the project team. These findings align with our research results in terms of project team importance, but there is no mention of the type of project team.

Another study conducted by Yamin, M. and Sim, A. K. S. [45] on international development projects used regression analysis to estimate the relationship between independent variables (monitoring, coordination, design, training and institutional environment) and project success. The main results revealed that monitoring has the most important impact in determining project success. The research results are based on the local project team perception, as the authors also state, which can be highly influenced by the national cultural features.

Regarding the second important factor-"organizational culture"-revealed by our study, it was not analyzed in any other research regarding international project success factors, which means that its impact is not visible enough or not yet fully understood.

The research has different limitations. The sample is non-random, since the volume of the total collectivity is unknown. The determination of the sample size was carried out in such a way as to reach the objectives of the study, taking into account the survey base, the available budget and the time period available. Under these conditions, the maximum admissible error and the level of confidence are impossible to calculate because they apply only to random samples. Other limitations about the sample are those relating to the respondents' nationality, since most were of Romanian nationality and the other nationalities could not form a critical mass. Thus, the collected data could have been influenced, to an important extent, by the cultural dimensions specific to Romanian culture. Nevertheless, it is possible that the intensity of national culture characteristics is diminished if respondents operate beyond the borders of the country of origin. Additionally, the responses of study participants may have been influenced by the level of education (by understanding the meaning of the terms used, taking into account that the questionnaire was written in English) and by their current mental state (referring to physiological, emotional, cognitive, moral and socio-relational states) at the time of completing the questionnaire. Another survey limitation is the fact that the participants were not questioned about the cost, size or the current project success. A larger and more rigorous sample could lead to new findings.

Thus, future research directions will have, as a starting point, the identified limitations, taking into account an improved sample and survey. We also consider an improvement of the methodology, using a multi-analytical approach, by completing the algorithm of neural networks with the PLS-SEM method, in order to have a stronger predictive model. Additionally, we will further explore the possibility of pairing causal inference and neural networks as machine learning algorithms, which might enable making a more "explainable prediction" [46].

\section{Conclusions}

The purpose of this research was to identify the factors that influence the success of international projects, to assess if the new type of team that has emerged due to technological advance could bring a new contribution to international project success and to understand the factors' behavior in order to ensure an efficient international project management. Following the literature review, eight important factors were identified. The survey results, first, were analyzed through descriptive statistics and also through factorial analysis (PCA), which helped us to reduce the number of factors to two main factors-the first factor, "Project Management", and the second factor, "External Factors". The PCA analysis results helped in preparing data for processing using a modeling technique, establishing the target variable needed for the neural networking algorithm. The data mining process using the IBM SPSS Modeler software made it possible to interpret the behavior of factors that influence international project success, which can be the starting point for future research studies, due to the accuracy of this method and the predictive model obtained. The results of the research are particularly important, emphasizing that setting up a project team in the virtual environment vs. a collocated team could make a major contribution to the 
success of international projects, validating the first hypothesis of the research. The new factor analyzed adds new dimensions to international projects, transforming them into IPTVEs. Regarding the organizational culture, which was the second most important factor in predicting international project success, an empirical study was conducted, and the proposed model with eight dimensions was validated, which will be presented in a future paper. In connection with the second research assumption regarding the correct and clear definition of the international project scope and objectives, this was also validated through the modeling technique, since it is the fourth factor in terms of importance in predicting international project success. This result states how important this factor is for project team performance, offering directions and cohesion for the project team in obtaining the best results. As for the third hypothesis, the predictive model did not validate it, since the "budget constraints" factor was the third in terms of importance in predicting international project success. This means that a flexible approach to project management, which goes beyond the triple constraint, is still not understood as viable in increasing the success rate of international projects.

Regarding the relevance of this research, we can state that, nowadays, international projects are developed in almost all sectors of activity because of their many benefits, and, as it is seen at this moment, for project managers, setting up a team in the virtual environment is considered as a constraint more than an advantage. Thus, this research offers a new way of approaching this situation, and starting with the idea that a team in the virtual environment becomes a factor that contributes to the project success can change the mindset of a project manager and begin to give the team in the virtual environment the necessary importance and specific management techniques in order to transform it into a valuable advantage in succeeding to achieve the stage of project success. Additionally, as the research did not analyze a particular type of international project, researchers can consider this study as a starting point to analyze specific IPVTEs, in different areas (IT, education, e-commerce, industry, etc.), adding distinctive factors which could bring new particular insights.

Author Contributions: All authors contributed equally to the writing of this paper and approved the final manuscript. Conceptualization, I.D.-B., D.-D.D. and G.D.; methodology, I.D.-B., D.-D.D. and G.D.; software, I.D.-B.; formal analysis, I.D.-B., D.-D.D. and G.D.; investigation, I.D.-B., D.-D.D. and G.D.; writing-original draft preparation, I.D.-B., D.-D.D. and G.D.; writing-review and editing, I.D.-B., D.-D.D. and G.D.; funding acquisition, I.D.-B., D.-D.D. and G.D. All authors have read and agreed to the published version of the manuscript.

Funding: The work of Iulia Dumitrașcu-Băldău was supported by the project "ANTREPRENORDOC", Contract no.36355/23.05.2019 POCU/380/6/13—Cod SMIS: 123847, financed by The Human Capital Operational Programme 2014-2020 (POCU), Romania.

Informed Consent Statement: Not applicable.

Data Availability Statement: Data is contained within the article.

Conflicts of Interest: The authors declare no conflict of interest.

\section{References}

1. Curlee, W.; Gordon, R.L. Complexity Theory and Project Management; John Wiley and Sons, Inc.: Hoboken, NJ, USA, 2011; ISBN 9780470769744.

2. Dunbar, G. Project Management Failures-Standish (Chaos) reports (1994-2015). 2016. Available online: https:/ /www.linkedin.c om/pulse/project-management-failures-standish-chaos-report-2015-dunbar (accessed on 9 September 2017).

3. Picciotto, R. Towards a 'New Project Management' movement? An international development perspective. Int. J. Proj. Manag. 2020, 38, 474-485. [CrossRef]

4. Dumitraşcu, I.; Dumitraşcu, D.D. Virtual Teams management in global international projects. Rev. Manag. Econ. Eng. 2015, 14, 691-701.

5. Davidavičienè, V.; Al Majzoub, K.; Meidute-Kavaliauskiene, I. Factors Affecting Knowledge Sharing in Virtual Teams. Sustainability 2020, 12, 6917. [CrossRef] 
6. Michaelides, R.; Bryde, D.; Ohaeri, U. Sustainability from a Project Management Perspective: Are Oil and Gas Supply Chains Ready to Embed Sustainability in Their Projects? Paper Presented at Project Management Institute Research and Education Conference, Phoenix, AZ. Newtown Square, PA: Project Management Institute. 2014. Available online: https://www.pmi.org/ (accessed on 12 January 2021).

7. Binder, J. Global Project Management; Gower Publishing Limited: Hampshire, UK, 2007; ISBN 9781409458104.

8. Köster, K. International Project Management; Sage: Thousand Oaks, CA, USA, 2010.

9. Dumitraşcu, I.; Dumitraşcu, D.D. How to face globalization challenges through international project management. Rev. Manag. Econ. Eng. 2015, 14, 467-476.

10. Atesmen, M.K. Global Engineering Project Management; CRC Press: Boca Raton, FL, USA, 2008.

11. Grisham, T.W. International Project Management: Leadership in Complex Environments; John Wiley and Sons: Hoboken, NJ, USA, 2011; ISBN 9781118276525.

12. ICB-IPMA Competence Baseline. 2006. Available online: http://www.ipma.world/assets/ICB3.pdf (accessed on 10 September 2018).

13. Shenhar, J.A.; Dvir, D. Reinventing Project Management; Harvard Business School Press: Boston, MA, USA, 2007 ; ISBN 9781422163474.

14. Popa, I. Management Strategic; Editura Economică: Bucureşti, Romania, 2004; ISBN 973-590-946-4.

15. Čiutienè, R.; Meiliene, E. Main Factors Influencing Efficient Planning of International Projects: Sample of High Schools International Projects. Procedia Soc. Behav. Sci. 2015, 191, 1506-1516. [CrossRef]

16. Lahiri, S.; Dhandapani, K. Project performance in emerging market: The influence of cultural distance and business group affiliation. Asia Pac. J. Manag. 2021, 38, 179-207. [CrossRef]

17. Hassan, F.A.; Ong'Ayo, H.A.; Osore, M.K. Assessing the Influence of Demographic Factors on Community Participation in a Demand Driven Development Project: The Case of Hazina Ya Maendeleo Ya Pwani Approach in Coastal Kenya. Open J. Soc. Sci. 2019, 7, 209-224. [CrossRef]

18. Kloppenborg, T.J.; Tesch, D.; Chinta, R.R. Demographic Determinants of Project Success Behaviors. Paper Presented at PMI ${ }^{\circ}$ Research Conference: Defining the Future of Project Management, Washington, DC. Newtown Square, PA: Project Management Institute. 2010. Available online: https:/ / www.pmi.org/learning/library/demographic-variables-project-success-f actors-6474 (accessed on 8 September 2016).

19. Yang, L.-R.; Huang, C.-F.; Wu, K.-S. The association among project manager's leadership style, teamwork and project success. Int. J. Proj. Manag. 2011, 29, 258-267. [CrossRef]

20. Hofstede, G.; Hofstede, G.J.; Minkov, M. Cultures and Organizations: Software of the Mind. Revised and Expanded, 3rd ed.; McGrawHill: New York, NY, USA, 2010; ISBN 9780071505680.

21. Pascu, R.V. Managementul Proiectelor; Editura Universitătii “Lucian Blaga”: Sibiu, Romania, 2010.

22. Davis, K. An empirical investigation into different stakeholder groups perception of project success. Int. J. Proj. Manag. 2017, 35, 604-617. [CrossRef]

23. Thomas, G.; Fernández, W. Success in IT projects: A matter of definition? Int. J. Proj. Manag. 2008, 26, 733-742. [CrossRef]

24. Radović Marković, M.; Markovic, D. Measuring Professional Competencies of Virtual Teams: Fuzzy-Logic Based Model. 2015. Available online: http:/ / ipsitransactions.org/journals/papers/tar/2014july/01.pdf (accessed on 20 November 2019).

25. Zofi, Y. A Manager's Guide to Virtual Teams; AMACOM: New York, NY, USA, 2012; ISBN 9780814416600.

26. Creasy, T.; Carnes, A. The effects of workplace bullying on team learning, innovation and project success as mediated through virtual and traditional team dynamics. Int. J. Proj. Manag. 2017, 35, 964-977. [CrossRef]

27. Brewer, P.E. International Virtual Teams: Engineering Global Success; (IEEE PCS Professional Engineering Communication Series); Wiley-IEEE Press: Hoboken, NY, USA, 2015; ISBN 9781119064084.

28. Dumitraşcu-Băldău, I.; Dumitraşcu, O. Research on the Behavior of Factors That Influence the International Virtual Project Team Performance, Using Data Modeling Techniques. Sustainability 2019, 11, 607. [CrossRef]

29. Settle-Murphy, N.M. Leading Effective Virtual Teams: Overcoming Time and Distance to Achieve Exceptional Results; CRC Press-Taylor \& Francis Group: Boca Raton, MA, USA, 2013; ISBN 9781466557871.

30. Lee, R.M. Leading Virtual Teams; CRC Press-Taylor \& Francis Group LLC: New York, NY, USA, 2014; ISBN 9781466576896.

31. Reed, H.A.; Knight, V.L. Project Risk Differences between Virtual and Co-Located Teams. J. Comput. Inf. Syst. 2010, 51, 19-30. Available online: https:/ / www.researchgate.net/publication/289588268_Project_risk_differences_between_virtual_and_co-lo cated_teams (accessed on 1 July 2016).

32. HBR-20 Minute Manager Collection. Leading Virtual Teams; Harvard Business Review Press: Boston, MA, USA, 2016; ISBN 9781633692381.

33. Saunders, M.; Lewis, P.; Thornhill, A. Research Methods for Business Students, 6th ed.; Pearson Education Limited: Essex, UK, 2012; ISBN 9780273750758.

34. Baker, R.; Brick, M.J.; Bates, N.A.; Battaglia, M.; Couper, M.P.; Dever, J.A.; Gile, K.J.; Tourangeau, R. Non-probability Sampling. 2013. Available online: https://www.aapor.org/Education-Resources/Reports/Non-Probability-Sampling.aspx (accessed on 5 July 2019).

35. McCormick, K.; Abbott, D.; Brown, S.M.; Khabaza, T.; Mutchler, S.R. IBM SPSS Modeler Cookbook; Packt Publishing Ltd.: Bir-mingham, UK, 2013; ISBN 978-1849685467.

36. Salcedo, J.; McCormick, K. IBM SPSS Modeler Essentials, Effective Techniques for Building Powerful Data Mining and Predictive Analytics Solution; Packt Publishing Ltd.: Birmingham, UK, 2017; ISBN 978-1-78829-111-8. 
37. Sören, G.; Wendler, T. Data Mining with SPSS Modeler, Theory, Exercises and Solutions; Springer International Publishing: Cham, Switzerland, 2016; ISBN 978-3-319-28709-6.

38. IBM Knowledge Center. Neural Net Node. Available online: https://www.ibm.com/support/knowledgecenter/en/SS3RA7_15 .0.0/com.ibm.spss.modeler.help/trainnetnode_general.htm (accessed on 5 July 2019).

39. IBM Software Group. IBM SPSS Modeler 17 Modeling Nodes. USA. Available online: https://public.dhe.ibm.com/software/an alytics/spss/documentation/modeler/17.0/en/ModelerModelingNodes.pdf (accessed on 1 August 2018).

40. Nisbet, R.; Miner, G.; Yale, K. Deep Learning. In Handbook of Statistical Analysis and Data Mining Applications; Academic Press. Elsevier: London, UK, 2018; pp. 741-751. [CrossRef]

41. Deep, A.I. Bias Vector. Available online: https://deepai.org/machine-learning-glossary-and-terms/bias-vector (accessed on 2 July 2019).

42. IBM Knowledge Center. Analysis Node Analysis Tab. Available online: https://www.ibm.com/support/knowledgecenter/en/S S3RA7_17.0.0/clementine/analysis_analysistab.html (accessed on 5 July 2019).

43. Tran, K.T. Critical Success Factors of International Projects in Vietnam. Int. Bus. Res. 2016, 10, 1. [CrossRef]

44. Alashwal, A.M.; Fareed, N.F.; Al-Obaidi, K.M. Determining Success Criteria and Success Factors for International Construction Projects for Malaysian Contractors. Constr. Econ. Build. 2017, 17, 62-80. [CrossRef]

45. Yamin, M.; Sim, A.K. Critical success factors for international development projects in Maldives. Int. J. Manag. Proj. Bus. 2016, 9, 481-504. [CrossRef]

46. Kuang, K.; Li, L.; Geng, Z.; Xu, L.; Zhang, K.; Liao, B.; Huang, H.; Ding, P.; Miao, W.; Jiang, Z. Causal Inference. Engineering 2020, 6, 253-263. [CrossRef] 